\title{
Intriga e narrativa. Duas operações da imaginação social
}

Ernesto Mora ${ }^{a}$

\begin{abstract}
Resumo
Neste artigo, examinamos a hipótese de que a narrativa e a intriga devem ser entendidas como dois conceitos diferentes no interior da teoria narrativa contemporânea. O argumento principal para sustentar essa distinção consiste na ideia de que tanto a narrativa quanto a intriga são operações cognitivas com fins específicos para diversas atividades humanas, especialmente, para a imaginação social. Tal distinção, aparentemente óbvia, é largamente negligenciada nas várias correntes atuais da teoria social que fazem uso do termo narrativa. Ao fazer isso, essas correntes limitam a análise dos potenciais cognitivos desse dispositivo do discurso. Com base nesse argumento, definiremos brevemente, em um primeiro momento, os conceitos de intriga e narrativa e, em segundo lugar, faremos uma discussão a respeito do retorno dos conceitos de estrutura e de sistema nos estudos da narrativa. Posteriormente, desenvolveremos algumas hipóteses sobre os aspectos cognitivos ativados pela construção da intriga e da narrativa. Finalmente, apresentaremos os vários aspectos da imaginação social nos quais os dois conceitos podem ser aplicados.
\end{abstract}

Palavras-chave: Intriga, narrativa, imaginação social. 
Para a teoria clássica narrativa ou para a narratologia em geral, a distinção entre a intriga e a narrativa pode parecer algo óbvio. A intriga, nomeada como mythos por Aristóteles, recebe vários nomes, especialmente nas teorias de composição de relatos, tais como plot, enredo, história etc. Ela é definida como a parte da narrativa na qual se expõe, de forma encadeada, uma série de acontecimentos que ocorrem a um ou a vários personagens. Esse encadeamento é o que os conduz de um estado a outro por meio de estágios decisivos, tais como "começo", "meio" e "desenlace". Para Aristóteles, a intriga era o coração das tragédias, hierarquicamente a sua parte mais importante e à qual todas as demais, como o caráter (ethos) e os diálogos (dianoia), deveriam estar subordinadas. Contudo, a evolução histórica dos relatos tem feito com que tanto essa divisão clássica quanto a própria hierarquia estabelecida pelo filósofo não se mostrem tão claras ou evidentes. Alguns autores como Paul Ricoeur defendem que, mesmo com as condições impostas pelas mudanças históricas aos marcos compositivos do relato, as funções próprias da intriga se mantêm imperturbáveis, pois elas correspondem a um tipo de inteligência universal que se mostra necessária para assuntos da vida prática, tais como a compreensão da temporalidade específica da vida humana ou a construção da identidade (RICOEUR, 1984, p. 32-58).

Neste artigo defendemos que, para os problemas da narratologia contemporânea, faz-se necessário pensar novamente a intriga e a narrativa como dois conceitos distintos, mesmo que complementares. A necessidade de tal distinção se explica quando, a nosso ver, um grande número de análises sobre a narrativa, especialmente no que tem a ver com seu uso em teoria social, assumem uma visão parcial do conceito de narrativa ao identificá-lo total ou parcialmente com o conceito de intriga. Nesses estudos, toma-se, digamos assim, a parte pelo todo.

Podemos identificar pelo menos cinco tipos de análise ou escolas teóricas que, apesar de adotarem o conceito de narrativa como central, tratam, na verdade, de teorias centradas na intriga.

Em primeiro lugar, há as teorias da decisão econômica, que entendem as narrativas como fazendo parte de ações estratégicas de persuasão e de cálculo entre custos e benefícios, 
feito pelos agentes racionais antes de tomarem um curso de ação (ABEL, 1987, 2003).

Em segundo lugar, encontram-se os enfoques culturalistas, que assumem as narrativas como discurso universal da cultura por meio do qual são absorvidos e dissolvidos os demais discursos (argumentações, interpretações, conversações) ou como lugar privilegiado da luta simbólica pelo poder social. Essa abordagem está presente nas correntes textualistas do pós-estruturalismo e nos estudos culturais (LYOTARD, 1979; DERRIDA, 1967; GIBSON, 1996; CURRIE, 1998; SALMON, 2007; JOHNSON-CARTEE, 2005).

Em terceiro lugar, estão as correntes que postulam uma função epistemológica meramente descritiva da ação social, como é o caso da fenomenologia e da etnometodologia (GARFINKEL, 2002; CLANDININ e CONNELLY, 2000; LUCIUS-HOENE e DEPPERMANN, 2000; ATKINSON, 1998; KONOPASEK e KUSA, 2000). No caso dessas correntes, reconhecem-se os conjuntos de regras e restrições que regem um contexto particular a partir do qual o sentido da ação particular pode ser explicado, mas não se leva em consideração como os próprios contextos podem ser imaginados, comparados e transcendidos pelos agentes narradores ou pelos personagens nas representações narrativas.

Em quarto lugar, encontram-se os estudos em psicologia moral que, baseados no componente narrativo de construção do self, sustentam uma oposição, às vezes tão radical quanto artificial, entre as teorias psicológicas cognitivistas, construtivas, formais e transculturais do desenvolvimento moral, como as de Piaget, Kohlberg e Turiel, e as posições social e culturalmente mediadas, multidimensionais, encarnadas em práticas e em discursos como os relatos (GILLIGAN, 1982; LARRABEE, 1993; TAPPAN e PARKER, 1991).

Finalmente, em quinto lugar, há as correntes filosóficas da narrativa, como as hermenêuticas, comunitaristas ou neoaristotélicas (MACINTYRE, 1981; TAYLOR, 1989; CARR, 1986; RICOEUR, 1990, 1991, 2004; NUSSBAUM, [1986], 2001, 1990). Essas teorias entendem que as narrativas funcionam como discursos de incorporação de normas e valores pelas identidades individuais ou comunitárias para além dos demais componentes ou sistemas da sociedade ou como discursos que atendem exclusivamente à perspectiva filosófica das éticas do bem. 
Nossa hipótese é a de que a narração e a intriga, mesmo funcionando em conjunto, devem ser novamente distinguidas em termos conceituais. Para sustentar essa hipótese, pretendemos definir os dois termos como modelos de operações cognitivas com características, funções e fins diferenciados, especialmente no que se refere ao seu enorme potencial para a cognição social. Assim, entendemos intriga e narrativa como competências específicas para a atividade maior da imaginação social em geral.

Inicialmente, podemos definir sinteticamente ambas as operações da seguinte forma: enquanto a intriga é uma associação imaginativa de uma(s) ação(ões) com outra(s), a narrativa é uma associação imaginativa de uma(s) ação(ões) com um contexto ou mundo narrativo.

\section{Definição de intriga}

Dizemos que a intriga é uma forma de associação imaginativa entre várias ações hipotéticas, realizada por meio de diversos recursos da linguagem e da ação. Em primeiro lugar, podemos associar duas ações em termos causais: uma ação seria o efeito da outra. Esse tipo de associação está presente, por exemplo, nos filmes de terror quando se mostra a imagem inicial de um zumbi seguida da imagem, em um plano distinto, do pânico da vítima. Também essa associação pode ser vista, nos filmes de ação, nos quais se mostra inicialmente a imagem de um carro em alta velocidade sendo atingido por outro e, em seguida, a imagem dele capotando e saindo da estrada. Em segundo lugar, é possível ligar as ações em termos lógicos. Esse tipo de ligação pode ser facilmente observado em relatos de detetives, que revelam não só a elevada competência desses profissionais para raciocínios do tipo lógico, mas também sua competência para antecipar os raciocínios lógicos dos assassinos ou ladrões. Em terceiro lugar, há as analogias. Na série de televisão The Wire, por exemplo, as ações sistemáticas e organizadas de grupos informais como as gangues são "análogas" (em sentido inversamente proporcional) à desordem e incomunicação das ações dos membros de instituições formais como a polícia. Finalmente, há as associações metafóricas, que são um tipo de associação na qual duas ações sem elementos comuns são 
implicadas por uma terceira que contribui para um significado novo (RICOEUR, 1975). ${ }^{1}$

Uma boa parte da teoria contemporânea da narrativa tem pensado as intrigas nos termos do que se chama "sentido". Esse pensamento é herdeiro tanto da filosofia hermenêutica quanto da teoria de ação econômica, assim como da teoria clássica de ação sociológica. Sentido seria um termo global que integraria todas essas formas de associação mencionadas (causal, lógica, analógica, metafórica) em uma estrutura maior que se basearia nos planos de ação que os personagens "dão" aos seus comportamentos, seguindo fins por "eles mesmos" desejados, ou nos planos de um narrador externo aos eventos que deseja levar os seus personagens a determinado fim. Pode-se atribuir sentido, partindo, por exemplo, dos objetivos particulares de cada ator em relação a uma ação específica (por exemplo, a ação de dinamitar uma caixa-forte com o objetivo de roubar o seu conteúdo); ou seguindo os desejos que o ator quer satisfazer, às vezes mesmo sem ele mesmo saber (como acontece em vários romances psicológicos ou nos chamados de "educação sentimental"); ou entendendo que os personagens são motivados por uma série de valores, a partir dos quais escolhem seus fins e, talvez, reprimam alguns de seus desejos. Finalmente, em maior grau de complexidade por implicar a associação de múltiplas ações, encontra-se o que alguns chamam de sentido de uma vida. Nesse caso, os atores se questionam: de que maneira posso associar alguns acontecimentos que já vivi de forma a dizer que a minha vida tem sentido? Como a organização das ações, relembradas por meio de uma intriga, dá sentido à minha vida?

É comum que, ao falar de sentido como o fio condutor das intrigas, façamos um encadeamento ou uma associação das ações de tipo teleológico, isto é, orientado ao cumprimento de um final que está nos planos ou nos desejos ficcionais dos personagens, ou então nos planos ou desejos do autor ou narrador do relato. A construção teleológica é um recurso cognitivo para ligar eventos e ações que por si sós não teriam ligação nenhuma. É a mente de um sujeito que cria e inventa

${ }^{1}$ Todas as notas no fim do texto. caminhos, padrões, rotas entre essas ações e por meio deles expressa um sentido completo em uma intriga. 


\section{Definição de narrativa}

Dizemos que a narrativa é uma forma de associação imaginativa entre uma ou várias ações e um contexto ou mundo hipotético. À semelhança do que ocorre com as intrigas, essas associações podem ser causais, lógicas, analógicas ou metafóricas. Aliás, elas podem não só modificar o sentido da intriga, mas limitá-lo a partir do sistema de restrições e recursos de determinado contexto. Da mesma forma, as narrativas também podem acolher uma diversidade de intrigas e confrontá-las entre si.

Esses contextos são variáveis e podem ser colocados, assim, em níveis a depender da distância à que estejam em relação aos atores e às ações que são contadas nos relatos. No cinema, por exemplo, essas variações são observáveis por meio do tipo de distância focal, do tipo de lentes utilizadas e da coleção de referentes que rodeiam a ação e os diálogos. Nos romances, essa mesma distância pode ser identificada, por exemplo, no uso das pessoas gramaticais, sendo que, em termos gerais, a primeira pessoa oferece contextos mais imediatos e subjetivos, enquanto a terceira, um panorama mais objetivo a partir do qual é possível observar os personagens e as suas interações à distância. Existe um termo técnico da teoria literária para tratar dessas variações: focalização.

A criação de contextos mais imediatos está muito relacionada com o tipo de experiência perceptiva, sensorial, emocional dos personagens com seu entorno e com as ações que os afetam. Esses contextos hipotéticos podem variar conforme imaginamos possibilidades de experiências singulares. ${ }^{2}$

Porém, tácita ou explicitamente, assumimos que todos os contextos pertencem a um mundo com determinadas ordens. Algumas dessas ordens são conjuntos complexos de regras que os personagens podem, talvez ou não, reconhecer ou dar por assentados. A esses macrocontextos chamamos de sistemas, que se definem pelas regras que os organizam. A suposição desses sistemas é um requisito heurístico para toda narrativa. Por exemplo, os sistemas naturais, isto é, os que estão organizados conforme as leis naturais (da física ou da biologia), são assumidos pelos espectadores ou leitores de narrativas que, na maioria dos casos, nem sequer questionam sua presença. Porém, os relatos de ficção científica, ao fazerem 
o experimento narrativo de modificar uma ou várias dessas leis naturais, acostumaram-nos a ver explicitamente esse tipo de sistemas. Por exemplo, eles nos mostram um mundo sem gravidade, um mundo de mais de três dimensões, uma atmosfera que nos faz envelhecer mais rápido etc.

Em todo caso, os relatos de ficção científica são uma minoria. Na verdade, na maioria das vezes os criadores de relatos jogam com outro tipo de regras: as regras sociais. Criar um mundo narrativo significa, de certa maneira, perguntarse pelas regras que conduzem as sociedades. A diferença é que as regras sociais são criadas e construídas pela espécie humana como recurso para a sobrevivência, qualidade de vida, comunicação, dominação e para outros objetivos. Por este motivo, essas regras não são escritas com os traços estanques das leis naturais, mas são mais volúveis, pois estão sujeitas à interpretação e, sobretudo, são modificáveis por meio de negociações, diálogos e lutas.

Outra característica das regras sociais é que elas não formam um único sistema acabado e holista que regula todas e cada uma das ações dos indivíduos. As regras sociais estão diferenciadas em grandes sistemas sociais (natural, econômico, cultural, normativo, pessoal), que são, em vários casos, conflitantes entre si. As narrativas seriam, pois, um enorme laboratório para se provar a modificação de algumas ou muitas das legislaturas dos sistemas sociais e as relações conflitantes ou pacíficas entre eles.

\section{Intriga e narrativa. $\mathrm{O}$ retorno às estruturas.}

Na Poética, quando são enumeradas as partes da tragédia, Aristóteles não só descreve as qualidades e funções de cada uma, mas prescreve seus usos corretos e, por fim, as dispõe em uma ordem hierárquica. A parte principal - a essência da tragédia - é, para Aristóteles, o mythos ou a intriga. Essa parte, que implica uma forma imaginária de associação entre ações, não só diz em que consistem as tragédias, mas estabelece os princípios básicos para a sua correta construção. A regra fundamental é a da verossimilhança, baseada nos princípios de probabilidade e necessidade. ${ }^{3}$ A regra de ouro da poética refere-se justamente ao critério de encadeamento das ações. Esse encadeamento não é definido pelo filósofo como "uma 
depois da outra" (tade meta tade), mas como "uma por causa da outra" (tade dia tade). Por um lado, a ligação entre os eventos representados não deve ser vista aos olhos do espectador como arbitrária, contraditória ou injustificada. Por outro lado, esse encadeamento, ao final, deve dar como resultado um todo com sentido. Por isso, para o relato não são importantes somente os fatos enquanto tais, mas, em primeiro lugar, a(s) ligação(ões) entre um(ns) fato(s) e outro(s) e, em segundo lugar, o papel que cada uma dessas ligações tem em uma estrutura global.

O grande problema que estaria nos bastidores do texto aristotélico seria, primeiramente, a falta aparente de lógica nos textos dos poetas, especialmente no germe dos mitos que lhes dão origem. E, em segundo lugar, estaria o resultado imprevisível dos fatos que seriam adversos aos planos dos personagens. Essa imprevisibilidade ocorreria em função de o todo resultante estar construído com base na procura da felicidade dos caracteres, como diz Aristóteles.

Sophie Klimis (1997) tem uma hipótese muito instigante para responder a esses problemas. Para a autora, a estrutura do mythos que Aristóteles expõe é um esforço de estandardização ideal das diversas formas de intrigas que se acumulavam nos festivais trágicos com o intuito de dar aparência lógica às incoerências e contradições que se apresentavam aos espectadores e, desta maneira, digamos, fazê-las produtivas, especialmente, para aspectos da vida prática. O principal efeito da intriga para os espectadores seria a catarse ou a purificação das paixões.

Os mitos nos quais se baseiam os relatos trágicos têm na sua base formas de representação lógica da realidade que contradizem expressamente as leis da física e da biologia aristotélica, como é especialmente o problema da simultaneidade dos contrários. A estandardização do mythos por meio da forte carga prescritiva que lhe dá Aristóteles é uma maneira de racionalizar os mitos para que guardem uma ordem homóloga à organização dos eventos da natureza na física e na biologia. Dois objetivos se cumpririam a partir desse esforço racionalizador aristotélico no contexto histórico do século IV: por um lado, continuar o caminho ininterrompido de secularização dos mitos que envolve a história do mundo helênico (KLIMIS, 1997); e, por outro, colocar esses mesmos mitos a jogar em favor de uma ética personalista que parte 
da escolha pessoal dos melhores fins ou bens e dos melhores caminhos (ligação de ações) para obtê-los (MACINTYRE, [1981], 2007; TAYLOR, 1989; NUSSBAUM, [1986], 2001). ${ }^{4}$

No século XX, a antropologia estrutural, os estudos históricos dos mitos e a narratologia procurariam, por um lado, rejeitar o suposto secular da suposta irracionalidade ou incoerência dos relatos ancestrais; e, por outro, contestar o império da intriga e a sua lógica de sucessão imposta desde a Poética. Em termos gerais, o que o estruturalismo e a mitoanálise descobriram é que os mitos obedecem a estruturas fechadas de relações entre seus componentes, isto é, os mitos se organizam em sistemas. Esses sistemas justapõem relações de coordenação, de oposição, de contradição em um todo unificado. Na verdade, observando já à distância, talvez se possa concluir que o estruturalismo deu ao mito a sua justa medida de razão ao considerá-lo uma rede total e fechada de relações lógicas. Os estruturalistas tinham a esperança de, por meio da análise das relações combinatórias do mito, dar explicações a traços antropológicos universais, em qualquer civilização, especialmente nas civilizações ocidentais que se sentem tão orgulhosas de demarcar com traços fortes aquilo que as separa dessa "consciência originária". O ponto central da antropologia estrutural estava no reconhecimento de que o "pensamento selvagem" estava no núcleo explicativo da cultura ocidental como um todo e, nesse caso, já não podia ser visto com a distância epistemológica característica da cultura científica. "Falar deles é falar de nós".

Porém, observando com a mesma distância, é constatável, no estruturalismo, uma sobrestimação do potencial do mito como dispositivo explicativo para as sociedades seculares modernas. ${ }^{5}$ Apesar de Aristóteles ser hoje o herói dos filósofos comunitaristas, os quais, em maior ou menor medida, defendem, contra a distância crítica e o objetivismo secular, a autoridade das tradições acumuláveis na interpretação de narrativas, ele continua a ser o grande ilustrado do mundo antigo, ${ }^{6}$ segundo nos mostra Sophie Klimis.

Contudo, talvez possamos ver agora que a pretensa distância da análise estrutural do mito em relação à intriga clássica não era tão forte assim. Em ambos os casos, trata-se de modelos simples altamente codificados de fabricação de narrativas. Os problemas epistemológicos do estruturalismo 
europeu nunca foram, na verdade, o apelo a sistemas ou estruturas, ou as suas pretensões de objetividade ou universalismo. Os déficits da análise estrutural são basicamente dois: em primeiro lugar, o abandono dos referentes, próprio da sua base teórica linguística; e, em segundo lugar, a concepção holista dos seus sistemas, ligados a uma lógica racional, porém elementar dos mitos. Com o primeiro problema, os estruturalistas perderam o mundo dos relatos e, com o segundo, o caráter aberto dos sistemas sociais.

O estruturalismo clássico está desde o início marcado pelo postulado saussuriano que divide o signo em significante e significado, prescindindo do aspecto referencial da linguagem. Assim, privilegiou-se sempre o código em detrimento da mensagem. Isto quer dizer que as estruturas que deveriam ser analisadas seriam simplesmente as que tomam como constituintes os componentes do sistema linguístico e, como conjunto de relações, as possibilidades combinatórias que há entre esses componentes. Essas combinações internas da linguagem como estruturas fechadas são mais importantes para o estruturalismo e a semiótica clássica do que os modos como as pessoas usam, por exemplo, as narrativas como complexos sistemas simbólicos para referir aspectos do mundo e da sua experiência (HERMAN, 2012).

Se nos usos cotidianos, expositivos ou comunicativos da linguagem, essa tendência consolidou um tipo de análise, ao menos, estranha; nos usos narrativos, deixou de lado o enorme peso do fenômeno de criação de referentes hipotéticos pelo discurso narrativo. No seu intento por emular as estruturas "harmônicas" do mito, a análise dos sistemas linguísticos e semióticos do estruturalismo perdeu o mundo.

Os estruturalistas tomaram esses sistemas de relações elementares do mito, desprovidos de seus referentes originais, e os entenderam como variáveis atemporais aplicáveis a qualquer sistema, inclusive aos sistemas sociais, que são dinâmicos em função, entre outras coisas, de suas regras serem modificadas por acordos, diálogos, lutas, negociações ou conflitos. Os sistemas semióticos do estruturalismo clássico e da antropologia estrutural eram, pois, sistemas sem mundo, surgidos a partir de mundos reduzidos em sua complexidade sistêmica. Portanto, seria impossível exigir deles a plasticidade que caracteriza a criação das narrativas das sociedades modernas. 
Essa última questão nos introduz ao segundo problema do estruturalismo: a impossibilidade de abertura de seus sistemas. O modelo fechado de relações entre os componentes mínimos dos mitos e também a normalização desses sistemas como base de análise de qualquer exemplo de narrativa, desconsiderando os referentes aludidos ou criados pelos relatos, mostrou-se rapidamente como um modelo limitado. Ao desligar a linguagem do mundo, o estruturalismo assentou as bases para uma definição artificial de narrativa. Desse modo, pode-se dizer que ele violentou a própria linguagem ao partir de uma análise de seu repertório de códigos, isto é, ao separar arbitrariamente as ferramentas de suas funções.

Os modelos mínimos da intriga baseada na sucessão e nos sistemas binários de oposição do mito mostrariam, contudo, um detalhe interessante em nível cognitivo e antropológico. Essa base sistêmica elementar poderia ter continuado a ser considerada como universal e sempre disposta a ativar-se na compreensão dos relatos. Porém, esse universal não poderia seguir sendo um núcleo explicativo oculto que a nossa civilização buscaria escavar para entender a si mesma. Mas, ao contrário, deveria ser visto como um dos conjuntos de leis e de relações entre elementos mais superficiais e evidentes da compreensão narrativa: um padrão cognitivo forjador e produto de hábitos. Com base nisso, poderia se explicar a sobrevivência das explicações míticas para fins cotidianos da seguinte forma: os mitos ainda são funcionais, em qualquer cultura, porque, em função de serem sistemas fechados de pensamento, oferecem soluções inquestionáveis para problemas práticos cotidianos. São úteis do ponto de vista pragmático, porém podem servir, do ponto de vista cognitivo, às lógicas de preservação do preconceito, enquanto recurso explicativo primário para ações sociais. ${ }^{7}$

Os sistemas fechados do mito assim o são porque neles estão misturadas, em uma mesma legislatura, as ordens da natureza, da sociedade, dos conteúdos da cultura e da personalidade (HABERMAS, [1981], 2010, p. 71-104). Apesar dos graus de complexidade real que as diversas culturas puderam alcançar, essa complexidade, pelo menos na forma como o estruturalismo entende os mitos, era reduzida a um sistema holista de correspondências. Uma chave para a compreensão da evolução das estruturas narrativas, assim como das sociedades, 
é o reconhecimento de processos de diferenciação de sistemas racionais. Assim, pois, como os estruturalistas descobriram, não é lícito falar do mito como "irracional", mas sim como fechado. Nas narrativas contemporâneas é impossível fazer essa redução holista do mito, pois os contextos que elas constroem obedecem a legislaturas diferenciadas. Em muitos casos, quase se poderia dizer que a chave de compreensão dos relatos está justamente nos lugares em que contextos com regulações diferentes se encontram e na forma como esses contextos afetam os personagens e as suas ações ${ }^{8}$.

\section{Aspectos cognitivos}

As associações hipotéticas ou imaginativas da intriga ou da narrativa supõem operações interdependentes, porém distintas em nível cognitivo. Nesse ponto, apresentamos algumas hipóteses a respeito de quais seriam essas operações e qual(is) a(s) sua(s) função(ões) cognitiva(s).

Em termos gerais, supomos que as operações da intriga, que associam ações entre si, estão mais ligadas às representações de atividades práticas dos indivíduos com objetivos específicos e direcionados, seja pelos próprios participantes ou por outros que exercem sobre eles algum tipo de poder.

Por outro lado, cremos que as operações da narrativa, que associam as ações com o mundo, estão mais ligadas às representações de imersão ou adaptação dos indivíduos a determinados contextos ou environments. Trata-se de como os indivíduos simulados são sensíveis aos ambientes naturais e sociais que os acolhem.

Com base nessa divisão operativa, podemos formular a hipótese de que na experiência e compreensão dos relatos estão em jogo de forma conjunta dois modos básicos de atividade cerebral: o modo focado (focused mode), que caracteriza as atividades direcionadas sobre objetivos explícitos, seguindo geralmente padrões neuronais já construídos a partir de atividades habituais; e o modo difuso (default mode), que caracteriza atividades sem propósito predeterminado, que ocorrem geralmente nos períodos de transição entre as atividades focadas (como nos momentos de descanso, quando tomamos banho, bebemos um café ou simplesmente sonhamos acordados). É esse último tipo de atividade cognitiva que, 
com base nos problemas das atividades focadas, procura novas ligações neuronais e associações inéditas, quando, por exemplo, os agentes encontram-se em ambientes desconhecidos (ANDREWS-HANNA, 2012; IMMORDINOYANG, 2012; RAICHLE, 2007).

Mesmo que a linha divisória não seja tão clara, a hipótese se formularia, nesse estágio e apenas como uma analogia, do seguinte modo: a intriga estaria para o modo focado como a narrativa, para o modo difuso.

Os esquemas da intriga, especialmente os mais tradicionais, operam sobre cognições aprendidas a partir de formas de comportamentos na vida prática. Os modelos clássicos dos relatos infantis e populares, como são aqueles classificados taxonomicamente por Vladimir Propp ([1928], 2006), constituem o exemplo paradigmático de construção de um padrão cognitivo de produção e recepção das histórias.

Os esquemas da narrativa operam sobre a familiaridade ou estranheza dos entornos que nos são apresentados nas intrigas e que aparecem, digamos, no background do nosso centro de atenção: nas cadeias de ações e eventos. A passagem de um personagem de um contexto a outro, como, por exemplo, o príncipe que se fantasia de mendigo e se insere no universo dos despossuídos, é o momento paradigmático em que os entornos passam ao primeiro plano de atenção dos espectadores.

As operações da intriga privilegiam a mimesis das tarefas que se sucedem no tempo por meio dos mais diversos modos de encadeamento, desde o mais simples, quando um evento é encadeado depois de outro, até os mais complexos, como ocorre em todas as variantes experimentais da temporalidade ficcional, como a novela ou o cinema contemporâneos. O foco continua sendo a sequencialidade, mesmo nos casos mais extremos de jogo com a ordem de encadeamento das ações. Assim, a questão que se faz, nesse caso, é: como podem ser organizados acontecimentos de ampla significação em uma sequência de passagens e de ações condizentes com determinado fim prático ou significativo em termos de composição? Seguindo uma velha caracterização do estruturalismo, poderia se dizer que a intriga opera sobre os elos sintagmáticos entre as ações conforme elas se atualizam na configuração de um relato, uma após a outra. Esses elos constroem para o ouvinte ou leitor uma imagem do modo como se desenvolvem as ações no tempo. 
Para isso, são estimulados processos mentais característicos das formas de memória: a expectativa (protensão) e a lembrança (retenção). Porém, as intrigas não só se serviriam desses processos, mas ajudariam a fixá-los como padrões habituais de cognição temporal. As estruturas homólogas dos contos, lendas populares e, em geral, de uma boa parte dos relatos épicos funcionam efetivamente sobre padrões fortemente estabelecidos filo e ontogeneticamente a ponto de suas estruturas permanecerem imodificáveis ao longo dos séculos sem perda de sua efetividade, como ocorre, por exemplo, no momento de se gerar surpresa ou suspense nos espectadores ou de se provocar determinadas emoções ou sentimentos 9 .

As finalidades práticas ou evolutivas que têm permitido o sucesso da intriga como operação cognitiva podem ser as seguintes:

(i) A consciência da irreversibilidade dos eventos e das ações que se sucedem no tempo. Isto é, sabe-se que não é possível desfazer um evento já acontecido nem mesmo tentar modificar as suas consequências;

(ii) A diferenciação entre momentos anteriores e posteriores, com base na situação ordenada de ações;

(iii) A consciência de que a identidade de um mesmo objeto, organismo e, sobretudo, de um indivíduo da espécie permanece a mesma, apesar de suas variações no tempo, como ocorre, por exemplo, na passagem da semente à árvore ou da criança ao adulto.

Já as operações da narrativa privilegiam a mimesis de mundos habitáveis nos quais as ações possam desdobrar-se. À diferença da ênfase em ações direcionadas, segundo fins atingíveis ou planos complexos de ação, a narrativa se relaciona com modos mentais de intuição global que fazem "imagens abrangentes" dos environments nos quais se inserem as ações, os planos de ação e as intrigas como tais. Três suboperações cognitivas, pelo menos, fariam parte da operação de narrar: o worldmaking, que seria a capacidade de imaginar mundos diferentes potencialmente habitáveis (HERMAN 2002, 2012, 2013a, 2013b; GERRIG, 1993; JAHN,1997); a imersão, que seria a capacidade de se inserir hipoteticamente nesses mundos, fazendo um balanço das potencialidades da ação, segundo um quadro de recursos e restrições que o contexto hipotético 
disponibiliza (RYAN 2001; CURRIE \& RAVENSCROFT, 2002); e a simulação, que implica a recriação de situações de ação específicas segundo a sua interação com o contexto e, especialmente, conforme a interação entre os próprios personagens imaginados. Fazem parte ainda da operação de narrar habilidades empáticas e reflexivas a respeito da posição e dos sentimentos dos outros - a habilidade para "se colocar nos sapatos do outro" (DOKIC \& PROUST, 2002: intro. vii; SCHAEFFER, 2013).

A metáfora dos simuladores espaciais é especialmente útil para compreender a função cognitivo-evolutiva das narrativas. Em um simulador espacial podem ser reproduzidas as condições atmosféricas e, em geral, os ambientes e ecossistemas que um cosmonauta teria de enfrentar em outro planeta ou lugar do espaço exterior. Por meio desse dispositivo, o futuro explorador treina a sobrevivência em contextos cujas leis naturais são radicalmente diferentes das leis físicas, químicas e biológicas do nosso planeta. Cria-se para ele um espaço no qual ele pode ingressar "como se" estivesse já naquela nova atmosfera e naquele novo ambiente ao qual terá de se submeter em suas próximas missões. Mesmo que ele não conheça ainda o espaço para o qual viajará, pode fazer o exercício de imersão em um espaço que faz "mimese" desse outro que realmente existe. A chave do simulador está em uma estrutura que funciona com leis idênticas ou aproximadas àquelas do environment que se pretende visitar na viagem espacial. O simulador é a criação de um sistema virtual construído segundo leis da natureza.

Muitas das narrativas de ficção científica seguem o mesmo padrão, já que constroem cenários nos quais são modificadas algumas ou muitas das leis às quais estamos acostumados (mudanças nas coordenadas espaço-temporais da física, lugares nos quais não envelhecemos, lugares nos quais os resultados biológicos da seleção das espécies são radicalmente distintos dos conhecidos pela história natural). Porém, diferentemente da ficção científica, na maioria das estruturas narrativas aquilo que é modificado nos contextos hipotéticos que rodeiam as ações dos personagens não são as leis naturais, que se caracterizam por aparecer em traços fortes, estáveis e dificilmente modificáveis, mas as leis sociais, que são, independentemente do seu grau de estabilidade, construções humanas que estão sempre submetidas a processos de mudança. Na maioria das ocasiões, os contextos sociais das 
narrativas têm diferenças apenas sutis em relação aos nossos contextos reais. Essa sutileza é, contudo, o espaço de um laboratório vastíssimo sobre as possibilidades de compreensão e mudança dos entornos sociais.

O potencial cognitivo das narrativas se relaciona diretamente com a habilidade para abrir o foco de sentido e de possibilidades, tanto das ações individuais e das situações de ação quanto das sequências completas de ação ou intrigas. Na mesma terminologia do estruturalismo que mencionamos acima, as narrativas dariam primazia aos elos paradigmáticos, isto é, ao espectro de possibilidades combinatórias entre as situações de ação e sequências de ação e os contextos diferentes que poderiam acolhê-las. A narrativa ativaria, então, uma capacidade imaginativa já não relacionada com o devir das linhas singulares da intriga, mas com a configuração de mapas gerais complexos, por meio dos quais é possível, em maior ou menor medida, refletir sobre a forma como várias ações e intrigas se entrecruzam segundo as determinações dos seus contextos. Sendo assim, a cognição narrativa já não está limitada exclusivamente aos jogos da expectativa (o suspense e a surpresa), ao sentido de um final, à lógica dos encadeamentos da intriga e à tensão entre os planos de ação e o devir ou destino. Trata-se de um mecanismo mais difuso, abertamente reflexivo, que procura potencializar a sensibilidade dos espectadores ou leitores em relação às ordens de configuração de mundos e à pergunta de como seria habitá-los.

\section{Aspectos da imaginação social}

A intriga como capacidade social tem sua função principal na construção e expressão da identidade individual e comunitária. Talvez a teoria narrativa de Paul Ricoeur seja o mais amplo esforço de descrição dessa capacidade veiculada no discurso narrativo. Ao poder unificar em uma intriga a suma de ações heterogêneas, significativamente diversas e temporalmente sem conexão, das quais tenho experiência enquanto indivíduo, posso reconhecer a mim mesmo em uma vida unitária com sentido. As intrigas têm o potencial cognitivo para fazer a síntese de acontecimentos dispersos; para predicar as diversas variações físicas, emocionais e intelectuais de um mesmo indivíduo; para apresentar de modo equilibrado a 
soma de ações que se sucedem coordenadamente segundo os planos de ação pessoais e de eventos que os interrompem discordantemente; e, em geral, para mostrar essa síntese produtiva de elementos como o modo melhor de dizer a identidade (RICOEUR, 1990, 1991).

Através da exposição das vidas pessoais na forma de intrigas, os sujeitos estendem aos outros o que poderíamos chamar de uma pretensão de identidade. Essa competência social pode ser observada, com toda a sua força, nos testemunhos e relatos das vítimas de determinado tipo de violência e nas reafirmações culturais de grupos minoritários e etnias ameaçadas por formas violentas de homogeneização cultural e lutas pelo poder.

Porém, a intriga, como competência sem o apoio da capacidade narrativa para "transcender" os contextos de emergência de onde surgem os fios de ação, pode ser responsável por um reforço cognitivo do preconceito ou da unilateralidade da violência, expressados em radicalismos culturais e ideológicos ${ }^{10}$.

Por um lado, sem uma visada abrangente das múltiplas intrigas em concorrência nos relatos das vítimas de qualquer forma de violência, podemos ser tentados, pelo poder da intriga, a dar primazia àquelas histórias com maior apelo emocional, com maior uso estratégico das técnicas do suspense e da surpresa, ou àquelas que utilizam com maior eficácia os recursos épicos de lutas diagramáticas entre bons e maus, oprimidos e opressores, dominados e dominadores. Seja através da narrativa ou de outras formas discursivas como as argumentações, é importante que a recepção social dos relatos de violência supere, em determinado estágio, os recursos da intriga, se é que se tem como objetivo social a equiparação em direitos de todos os grupos de vítimas de violência que lutam pela obtenção de determinados espaços de reconhecimento ${ }^{11}$.

Por outro lado, embora as intrigas comunitárias sirvam como mecanismos de reconhecimento e pertença dos indivíduos a suas comunidades - são desenvolvidas por meio delas competências sociais como a solidariedade e a coordenação motivada de interesses e valores, sem os recursos da narrativa para sensibilizar quanto à diferenciação das sociedades em sistemas (cultural, econômico, normativo e pessoal), o reforço social exagerado das intrigas como recurso comunicativo leva 
à fixação cognitiva unilateral das leis de um sistema, sem que se possa contrastá-las com as regulações dos outros sistemas. São exemplares os casos daquelas comunidades religiosas muito fechadas que, em certas ocasiões, atuam com base em formas comunicativas de legitimação do agir, fundamentadas exclusivamente nos ditados das intrigas apresentadas em seus livros sagrados. Assim, as regras da cultura particular se tornam onipotentes, impermeáveis e não dialogantes, por exemplo, com as normas cidadãs ou com as liberdades pessoais.

A narrativa, que é, em termos gerais, uma competência mais abrangente que a intriga e se relaciona com a imaginação social, equivaleria a um processo cognitivo por meio do qual se faz o exercício discursivo de colocar uma situação de ação "imaginada" em relação a um contexto hipotético de recursos e restrições que, ao mesmo tempo em que dá significado a essa situação de ação, antecipa, em um espectro aberto de possibilidades, seu desdobramento.

Três elementos entrariam como variáveis compositivas e compreensivas da definição anterior: os contextos hipotéticos, as situações de ação hipotéticas e o discurso narrativo. Por razões de espaço, vamos nos limitar, neste artigo, a apresentar apenas os dois primeiros.

Em primeiro lugar, os contextos narrativos comportam legislaturas hipotéticas que tecem o pano de fundo no qual se desdobram as ações. Os contextos sociais, como dissemos anteriormente, não obedecem a apenas uma legislatura, mas são constituídos por variadas legislaturas. Aqueles contextos que superam a particularidade dos entornos próximos aos personagens e que se apresentam como tipos formais em qualquer sociedade se definem como sistemas ${ }^{12}$.

Os sistemas sociais não são, em termos gerais, harmônicos. As sociedades modernas ganharam, nos processos de diferenciação das suas esferas do agir (sistemas), os espaços de liberdade em valores e em poder de decisão, de inclusão e de discussão. Ao contrário, às comunidades dependentes de leis holistas e não diferenciadas não são permitidos esses espaços de liberdade ${ }^{13}$. Porém, o preço a se pagar, nas sociedades modernas, por esse pequeno espaço de liberdade está caracterizado pelas constantes dissonâncias entre os diferentes conjuntos de regulações. As normas jurídicas de sociedades laicas, por exemplo, podem representar uma 
ameaça a princípios de forte arraigamento cultural em determinadas comunidades, como é o caso das questões que envolvem o aborto ou o matrimônio homossexual, por exemplo. As promessas de inclusão social, contidas normativamente nas constituições nacionais, colidem fortemente com os interesses e lutas de poder característicos dos sistemas econômicos. Além disso, os planos de construção da identidade pessoal podem chocar-se com freios de todo tipo, como os traços culturais do entorno familiar, as privações no aparato público de bem-estar ou as normas jurídicas não inclusivas.

O potencial cognitivo da narrativa é não só fazer mimese do funcionamento regulado de cada um desses contextos em casos imaginários, mas algo muito mais interessante: servir de laboratório hipotético para as diferentes formas como se colidem tais sistemas e como se organizam entre si. As narrativas desenham mapas nos quais se representam as volúveis divisas que caracterizam os mundos sociais. O modo como tais divisas são transformadas depende de inúmeras situações de ação de tipo dialógico-comunicativo, de negociações ou de conflitos e lutas abertas. A narrativa é, assim, um dispositivo que pode servir à reflexão desinteressada e meditativa das mudanças históricas das sociedades.

Em segundo lugar, as situações hipotéticas de ação estimulam a identificação de tipos abrangentes ou ideais de situações de ação, a partir de um critério particular ${ }^{14}$. Uma divisão simples desses tipos ideais pode ser a que diferencia as relações sociais como cooperativas ou concorrentes (BUNGE, 1996). Preferimos, entretanto, pensar em um esquema muito mais nutrido, como o apresentado por Habermas na obra Teoria do agir comunicativo, na qual a classificação é feita conforme as racionalidades diferenciadas, comumente reconhecidas, isto é, diferentes formas de inteligência para as interações ${ }^{15}$.

Um aspecto notável que diferencia a narrativa e a intriga, neste ponto, é que as intrigas privilegiam a mimese dos dilemas clássicos da ação teleológica, isto é, os problemas relacionados com as tomadas de decisão estritamente individuais ou comunitárias, mediante as quais são geradas expectativas nos espectadores quanto à fortuna ou ao fracasso dos planos de ação dos personagens. Existem, assim, dois tipos paradigmáticos de dilemas da intriga sobre os quais há abundante literatura 
nas análises narrativas: os dilemas da escolha racional ou da decisão econômica e os dilemas morais ${ }^{16}$.

Já na cognição narrativa aparecem novos tipos de dilemas, aos quais podemos chamar, por enquanto e à falta de outro nome, de dilemas sociológicos. A análise narrativa orientada para tais formas de dilema vê, nos relatos, dispositivos que sensibilizam o intérprete para as grandes exigências que os sistemas sociais fazem aos personagens, sendo que estes, em determinados momentos, se veem na situação de ter que responder às regulações contraditórias de dois ou mais sistemas. Exemplo disso são os conflitos cujo paradigma é, certamente, Antígona: os personagens devem escolher entre seus imperativos culturais religiosos e aqueles que são ditados por exigências jurídicas.

Em uma entrevista para a revista The Believer, David Simon, o criador da série de televisão The Wire, falou, mais ou menos, o seguinte: parece-nos a nós, modernos, que assuntos como o destino ou a fortuna (elementos característicos das estruturas clássicas da intriga) já não fazem parte de nossos modos de raciocinar e agir, pois já não atribuímos nosso sucesso ou fracasso à força inexpugnável e incompreensível de deuses e entidades que têm escrita para nós uma intriga da qual não temos noção. Isto é verdade, diz Simon, porém, podemos falar metaforicamente de destino em nossa sociedade contemporânea e nossos deuses se chamam instituições. As instituições representam sistemas organizados que estabelecem as normas a serem seguidas por todos aqueles que pertencem a uma sociedade determinada. Contudo, quando elas resultam tão autônomas, enormes e disfuncionais, ao contrário de serem a base integrativa das sociedades modernas, tornam-se como deuses que fazem exigências contraditórias aos indivíduos. Estes acabam, então, por depender de funções e interesses que se ocultam a eles e por se submeter aos devires de uma luta sobre a qual já não têm controle, mas da qual sofrerão as consequências, como se estivessem sujeitos de novo às fúrias, aos ciúmes e aos estados de ânimo dos deuses do Olimpo (HORNBY, 2007).

Por outro lado, tais como explicados por Martha Nussbaum em A fragilidade da bondade, os dilemas morais podem ser vistos segundo a perspectiva dos chamados momentos trágicos. São estes os momentos nos quais um personagem deve decidir entre duas linhas de ação (ambas 
justificáveis), as quais trarão consequências ruins para os outros personagens a ele vinculados afetivamente. Por exemplo, Agamenon deve decidir entre o sacrifício de sua filha ou o salvamento do seu exército, pois os deuses assim o exigem. Para Nussbaum, as ponderações individuais que estão em jogo nos momentos trágicos dependem de exercícios fundamentais de autoconhecimento que envolvem a vida como um todo. Reexaminar uma vida boa com esmero é um exercício que implica o reconhecimento da fragilidade mediante o cultivo e aprimoramento das emoções, o cuidado com a vida dos outros e a adequação dos sentimentos às decisões tomadas nos cursos da ação (NUSSBAUM, [1986], 2001).

Na contemplação da vida boa como um todo e no reconhecimento de sua fragilidade nos momentos trágicos se encontraria o patamar máximo do poder reflexivo das intrigas. Contudo, a reflexão narrativa não tem por que se deter neste ponto. Afinal, as instituições só se comportam como deuses na óptica de sujeitos particulares envolvidos em suas intrigas de planos e desejos. As narrativas têm o poder de transcender as intrigas e sensibilizar o intérprete quanto às estruturas das instituições. É justamente isso o que acontece em séries como The Wire, em A comédia humana de Balzac ou em $A$ cidade e os cachorros de Mario Vargas Llosa. As narrativas colocam os leitores perante a fragilidade dos "deuses", isto é, das instituições humanas e de seus modos, às vezes incertos, de coagir ou libertar os seres que as criaram ou delas dependem.

\section{REFERÊNCIAS}

ABEL, P. The Role of Rational Choice and Narrative Action Theories in Sociological Theory: The Legacy of Coleman's Foundations. Revue Française de Sociologie, 44, 2003, p. 255-273. The Syntax of Social Life: The Theory and Method of Comparative Narratives. Oxford: Oxford UP, 1987.

AMSTERDAM, A. G.; BRUNER, J. Minding the Law. Cambridge, Mass.: Harvard University Press, 2002.

ANDREWS-HANNA, J. R. The Brain's Default Network and Its Adaptative Role in Internal Mentation. Neuroscientist, 18, 2012, p. 251-70. 
ARISTOTE. La Poétique (Dupont-Roc, Roselyne et Lallot, Jean Trans.). Paris: Seuil, 1980.

ATKINSON, R. The Life Story Interview (Qualitative Research Methods series 44 ed.). London: Sage, 1998.

BRUBAKER, R.; COOPER, F. Beyond 'Identity'. Theory and Society, 29, 2000, p. 1-47.

BRUNER, J. Making Stories. Law, Literature, Life. Cambridge, Mass.: Harvard University Press, 2003.

BRUNER, J. The Narrative Construction of Reality. Critical Inquiry, 18, 1991.

BUNGE, M. Buscar la filosofía en las ciencias sociales. Madrid: Siglo XXI, 1996.

1995.

. Sistemas sociales y filosofía. Buenos Aires: Sudamericana,

Social Science under Debate: A Philosophical Perspective. Toronto: University of Toronto Press, 2000.

Treatise on Basic Philosophy. IV: Ontology: A World of Systems. Dordrecht: Reidel, 1979.

CARR, D. Time, Narrative and History. Bloomington: Indiana UP, 1986.

CASSIRER, E. O mito do estado. [1946] São Paulo: Codex, 2003. CLANDININ, D. J.; CONELLY, F. M. Narrative Inquiry: Experience and Story in Qualitative Research. San Francisco: Jossey-Bass, 2000.

CURRIE, G.; RAVENSCROFT, I. Recreative Minds. Oxford: Oxford UP, 2002.

CURRIE, M. Postmodern Narrative Theory. London: Macmillian, 1998.

DERRIDA, J. De la Grammatologie. Paris: Minuit, 1967.

DOKIC, J.; PROUST, J. Simulation and Knowledge of Action. Amsterdam: Benjamins, 2002.

FERRY, J. La ética reconstructiva. Bogotá: Siglo del Hombre, 2001. GARFINKEL, H. Ethnomethodology's Program: Working out Durkeim's Aphorism. Ed. e introd. A. Rawls. Oxford, UK: Rowman \& Littlefield, 2002.

GERRIG, R. Experiencing Narrative Worlds: On the Psychological Activities of Reading. New Haven: Yale UP, 1993. 
GIBSON, A. Towards a Postmodern Theory of Narrative. Edinburgh: Edinburgh UP, 1996.

GILLIGAN, C. Different Voice: Psychological Theory and Women's Development. Cambridge: Harvard UP, 1982.

HABERMAS, J. Teoría de la acción comunicativa. [1981] Madrid: Trotta, 2010.

HABERMAS, J. Teoría de la acción comunicativa. complementos y estúdios previos. [1984] Madrid: Cátedra, 1997.

HERMAN, D. Approaches to Narrative Worldmaking. In: ANDREWS, M. (Ed.), Doing Narrative Research. London: Sage, 2013b, p.176-195.

Story Logic: Problems and Possibilities of Narrative. Lincoln: U of Nebraska P, 2002.

Storytelling and the Sciences of Mind. Cambridge: MIT P, 2013a.

HERMAN, D. (Ed.). Narrative Theory: Core Concepts and Critical Debates. Columbus: Ohio State UP, 2012.

HORNBY, N. Interview with David Simon.The Believer, 5, 2007. IMMORDINO-YANG, M. H.; CRISTODOULOU, J.; SINGH, V. Rest is Not Idleness: Implications of the Brain's Default Mode for Human Development and Education. Perspectives on Psychological Science, 7, 2012, p. 352-64.

JAHN, M. Frames, Preferences, and the Reading of ThirdPerson Narratives: Toward a Cognitive Narratology. Poetics Today, 18.4,1997, 441.

JOHNSON-CARTEE, K. S. News Narratives and News Framing: Constructing Political Reality. Oxford, UK: Rowman \& Littlefield, 2005.

KLIMIS, S. Le Statut du mythe dans la poétique d'Aristote. Le fondements philosophiques de la tragédie. Bruxelles: Ousia, 1997.

KONOPASEK, Z.; KUSA, Z. Political Screenings as Trials of Strength: Methodological Consequences of the Relativist Perspective in Oral History Research. In: KOLEVA, D. (Ed.), Talking History (2000). Sofia: LIK, 2000.

LARRABEE, M. J. (Ed.). An Ethic of Care. Feminist and Interdisciplinary Perspectives. London: Routledge, 1993. 
LUCIUS-HOENE, G.; DEPPERMANN, A. Narrative Identity Empiricized: A Dialogical and Positioning Approach to Autobiographical Research.Narrative Inquiry, 10, 2000, p. 199-222. LYOTARD, J. La Condition postmoderne. Rapport sur le savoir. Paris: Minuit, 1979.

MACINTYRE, A. After Virtue. [1981] Notre Dame, IN: University of Notre Dame Press, 2007.

NUSSBAUM, M. The Fragility of Goodness: Luck and Ethics in Greek Tragedy and Philosophy. [1986] New York: Oxford University Press, 2001.

NUSSBAUM, M. Love's Knowledge: Essays on Philosophy and Literature. New York: Oxford UP, 1990.

PROPP, V. ([1928] 2006). Morfologia do conto maravilhoso. [1928] Rio de Janeiro: Forense Universitária, 2006.

RAICHLE, M.; MACLEOD, A.; SNYDER, A.; POWERS, W.; GUSNARD, D.; SHULMAN, G. A Default Mode of Brain Function. Neuroimage, 37, 2007, p. 1083-90.

RICOEUR, P. Caminos del reconocimiento. [2004] Madrid: Trotta, 2005.

. L'Identité narrative. Revue Des Sciences Humaines. Paris, Janviers-Mars 1991, p. 35-46. . La Métaphore vive. Paris: Seuil, 1975. Soi-même comme un autre. Paris: Seuil, 1990.

. Temps et récit. 1. L'intrigue et le récit historique. Paris: Seuil, 1983.

. Temps et récit. 2. La configuration dans le récit de fiction. Paris: Seuil, 1984.

Temps et récit. 3. Le temps raconté. Paris: Seuil, 1985.

RYAN, M. Narrative as Virtual Reality. Immersion and Interactivity in Literature and Electronic Media. Baltimore: Johns Hopkins UP, 2001.

SALMON, C. Storytelling: La machine à fabriquer des histories et a formater les sprits. Paris: La Découverte, 2007.

SCHAEFFER, J. M. Fictional vs. Factual Narration.The Living Handbook of Narratology, 2013. Disponível em http://www.lhn. uni-hamburg.de/. Acesso em 16 nov. 2015. 

SCHLUCHTER, W. Acción, orden y cultura. Buenos Aires:
Prometeo, 2008.

TAPPAN, M. B.; PACKER, M. J. Narrative and Storytelling: Implications for Understanding Moral Development. San Francisco: Jossey-Bass, 1991.

TAYLOR, C. Sources of the Self. Cambridge: Cambridge University Press, 1989.

WEBER, M. Economía y sociedad. [1922] México: Fondo de Cultura Económica, 1984.

\footnotetext{
${ }^{1}$ Na série de televisão Boardwalk Empire, a personagem Margaret, imigrante russa e nova mulher de Nucky Thompson, o maior traficante de álcool de New Jersey dos anos 1920, vê passar o avião pilotado por aquela que dizem ser a primeira mulher aviadora, segundo as manchetes de jornal. Essa visão serve como uma metáfora que liga a condição atual da personagem aos seus desejos de mudança de plano de vida.

${ }^{2}$ Por exemplo, no filme Repulsão, a protagonista sofre de esquizofrenia e sua doença se ativa quando ela fica sozinha. Nesse momento, as dimensões do seu apartamento se expandem e o espaço se deforma até o ponto em que as paredes ficam moles e delas surgem muitas mãos que perturbam a jovem. Os contextos imediatos também podem atender a pequenos rituais de interação, como, por exemplo, o contexto de uma turma de amigas que se reúnem para desabafar sobre seus casamentos.

3 Outras partes da tragédia são o ethos, que se refere ao caráter (elevado ou baixo) dos personagens e a dianoia, que diz respeito ao discurso. Essas três partes - mythos, ethos e dianoia - constituem os objetos da tragédia, "o quê" ou aquilo sem o qual não teríamos tragédia nenhuma. Mesmo que as três sejam importantes, Aristóteles é enfático em priorizar o primeiro e em colocar o ethos e a dianoia a jogarem a serviço da intriga.

${ }^{4}$ Além da coerência artificial que o mythos ofereceria às ações contraditórias, o outro grande assunto que a estrutura da intriga soluciona é o assunto da imprevisibilidade dos eventos, se levarmos em conta os planos de ação dos atores. A elaboração de um plano de ação por um ou mais personagens deve se encontrar de frente com circunstâncias inesperadas que podem quebrar aquela ordem que, pelo menos para os atores, guardava certo sentido - o sentido dos seus planos e desejos. Aristóteles introduz então o termo metabole ou "reviravolta", que contempla esses giros do imprevisível na cadeia de ações ordenada segundo os planos em procura da felicidade dos atores. Klimis assegura que, longe de esse recurso ser um acréscimo colateral à estrutura das intrigas para solucionar o problema do destino, trata-se de um recurso análogo às leis do movimento na física e na biologia. Assim como o movimento implica a passagem dos entes de um estado a outro e, na biologia, o movimento é o impulso motor do previsível no reino natural, a mudança é o impulso motor do imprevisível na ação humana presente nas intrigas. Explicam-se aos homens aqueles eventos para os quais nenhuma previsão é previsível (passagem da fortuna ao infortúnio, ou passagem do desconhecimento ao reconhecimento). Porém, em ambos os casos, tanto na coerência do sentido da ação quanto nas "reviravoltas", pa-rece que no fundo da organização da intriga, segundo Klimis, está a indagação por sua utilidade heurística, isto é, por resolver um problema cognitivo para as ações práticas, nos termos atuais.

${ }^{5}$ Já antes da febre estrutural, Ernst Cassirer advertiu que a exaltação do jogo fechado de relações dos mitos funcionaria como um antídoto eficiente contra a crítica, a liberdade racional e a transformação social; além de servir ao mesmo tempo como justificativa e estímulo a poderes totalitários (CASSIRER, [1946], 2003).

${ }^{6} \mathrm{Na}$ análise estrutural, a lógica do mito virou, então, moeda corrente para explicar tudo: as tensões trágicas como pulsões arcaicas na Atenas supostamente racional e democrática; os mitos explicativos da conduta como o fundo do inconsciente, na psicanálise freudiana, ou do inconsciente coletivo, na jungiana. A interpretação na chave do desvelamento mítico invadiu também as análises de crítica literária que intentavam codificar uma enciclopédia simbólica dos elementos pulsionais ancestrais de toda a novela contemporânea. A rotina epistemológica do estruturalismo antropológico consistiu na arte de "desocultação" do núcleo mítico de qualquer elemento da cultura contemporânea.

É este, claramente, um hábito que fez sucesso na subsequente escola pós-moderna e nos estudos culturais, os quais se encarregam de mostrar as "lógicas" ocultas do poder, os conteúdos inibidos e reprimidos das culturas, a domesticação dos corpos mediante técnicas de governabilidade etc. O único que mudou neste caso foi o apelo à universalidade e à pretensão de cientificidade do estruturalismo, que ainda era visto como um objetivo inerente às faculdades e institutos de pesquisa.
} 
7 A atualidade do mito pode ser vista, por exemplo, no jogo de expectativas e de mecanismos da justiça da compensação (a toda ação má corresponde um efeito negativo sobre aquele que a efetua, e toda ação justa supõe uma recompensa equivalente). Trata-se de uma justiça intuitivista, que faz com que seja quase automático nos indivíduos o apelo ao punitivismo (castigos como a prisão, a morte ou a violência) ou à premiação dos vingadores para dar solução aos problemas de insegurança e crimi-nalidade. As narrativas épicas reeditam, a cada vez, a lógica de corres-pondências holistas do mito: a justaposição de valores morais a atributos físicos que, por sua vez, são um reflexo de potências da natureza. São exemplos disso as sagas como O Senhor dos Anéis, ou as revisitações épicas dos conflitos bélicos, como Troia, Braveheart etc.

8 O momento central do filme The Last Emperor, de Bernardo Bertolucci, é aquele em que o jovem monarca finalmente decide escalar o muro que separa a cidade proibida do resto do mundo. Quando ele se apoia na borda da parede e observa pela primeira vez o universo enorme que se abre ao seu redor, está, literalmente, na fronteira entre dois sistemas sociais radicalmente diferentes cujas leis são opostas e conflitantes. Essa imagem serve de me-táfora para a "colisão" contínua de contextos que caracteriza as socie-dades modernas. Agora, esse é, digamos, o exem-plo extremo, pois, na maioria das vezes, tra-ta-se de divisas sutis e dinâmicas.

9 As paródias dos mitos populares e de suas versões contemporâneas, como são, por exemplo, os filmes e esquetes do coletivo Monty Python, só são efetivas por conta da sensação de estranheza que a ruptura causa em relação ao padrão da intriga que se tem naturalizado enquanto operação cognitiva (por exemplo, ao se modificar em paralelo os personagens e as intrigas bíblicas, como acontece em A vida de Brian).

${ }^{10}$ Para uma discussão mais geral sobre a ne-cessidade de superação em nível teórico e epistemológico do conceito de identidade, ver o artigo "Beyond 'identity'". (BRUBAKER e COOPER, 2000)

${ }^{11}$ Caso especial é o direito à memória, que depende em alto grau do conhecimento da "verdade" daquilo que aconteceu mediante a exposição de intrigas. Nos contextos com histórico de violência crônico que impacta múltiplos atores e múltiplas manifestações do vexame, os centros de memória não devem se transformar em espaços que reproduzam o mesmo estilo de concorrência entre intrigas que caracteriza os meios oficiais e não oficiais de informação. Nesses contextos, deve-se procurar "transcender" o particularismo das intrigas aí expostas para se oferecer a todas as vítimas um espaço equilibrado de comemoração. (FERRY, 2001, p. 31-41).

12 Podemos nomear pelo menos cinco sistemas que dão sentido à ação social: o sistema natural, baseado em leis da natureza; o sistema econômico, baseado em leis dos intercâmbios materiais e das determinações de classe ou estrato; o sistema cultural, formado por regulações próprias de religiões, formas de vida, ideologias, filosofias, cosmovisões etc.; o sistema normativo, constituído de normas abertas e escritas, que são construídas cooperativamente e transformáveis por meio de procedimentos institucionais de discussão e que afetam todos os implicados na medida em que se tenta abstraí-los (tanto quanto possível) de suas filiações culturais ou econômicas; e o sistema da personalidade, que é a soma de capacidades individuais, socialmente reconhecidas, por meio das quais os sujeitos podem construir sua identidade.

Nessa classificação, integram-se as tradições de compreensão dos sistemas sociais das obras de Habermas e Mario Bunge. O que Habermas, seguindo Parsons, chama de Sociedade, é o que aqui entendemos como sistema normativo. Sociedade, cultura e personalidade (a clássica divisão de Parsons) são todos, nessa óptica, sistemas sociais (HABERMAS, [1981], 2010). Já seguindo a classificação mais dinâmica de Mario Bunge, esses três sistemas (normativo, cultural e pessoal) devem ser complementados com o sistema econômico e biológico (BUNGE, 1979, 1995, 2000).

${ }^{13}$ Fala-se aqui de casos gerais ou "tipos" de sociedades e é claro, nesse sentido, que a linha divisória entre umas e outras não é tão nítida. Aspectos de pensamento holista persistem em sociedades diferenciadas ao passo que comunidades com fortes rasgos identitários têm se incorporado sem dificuldades às sociedades complexas, acrescentando novas e produtivas variáveis de diferenciação. São exemplos de formas de pensamento holista os comportamentos comunitários segundo os quais toda decisão depende dos ditados de um código sagrado, ou da interpretação simbólica dos acontecimentos por parte de eruditos consagrados, ou de hierarquias inalteráveis do poder econômico como nas comunidades organizadas por castas. 


\section{Abstract \\ Plot and narrative. Two operations of social imagination}

This article develops the hypothesis that narrative and plot should be understood as two distinct concepts within contemporary narrative theory. The main argument for this distinction is that both narrative and plot are cognitive operations with specific purposes for different human activities, especially social imagination. This distinction, apparently obvious, is largely neglected in various contemporary currents of social theory when they use the term narrative. In so doing, they limit the analysis of the cognitive potential of this kind of discourse. This study will first present summarized definitions of both terms. This will be followed by a short excurse on the return of the concepts of structure and system within narrative studies. Third, it will introduce hypotheses about cognitive aspects activated by plot and narrative. Finally, various aspects of social imagination in which the two concepts could be applied will be presented.

Keywords: plot, narrative, social imagination. 